\title{
Forgotten Wishes: End-of-Life Documents for Trans People with Dementia at the Margins of Legal Change*
}

\author{
Alexandre Baril, Marjorie Silverman, (D) Marie-Claire Gauthier and \\ Maude Lévesque
}

\begin{abstract}
Literature on the topic of trans older adults has documented a few anecdotal cases in which some trans people living with dementia forgot they transitioned and reidentified with their sex assigned at birth ("detransition"). Trans communities and their allies have encouraged trans people to engage in end-of-life planning, including the preparation of legal documents that state their wishes regarding gender identity and expression in the event of "incapacity" caused by dementia. While useful, we contend that end-of-life planning is often implicitly based on cisnormative and cognonormative (normative system based on cognitive abilities) assumptions. Such planning is founded on a stable notion of gender identity throughout the life course ("post-transition") and assumes that the pre-dementia self is better equipped to make decisions than the "demented" self. We conclude by encouraging, based on an intersectional, trans-affirmative, crip-positive, and age-positive approach, respect for the agency of trans people with dementia.
\end{abstract}

Keywords: Trans and nonbinary people, end-of-life planning and documents, cisgenderism/transphobia, ableism/cogniticism, ageism, epistemic injustices.

\section{Résumé}

Les écrits portant sur les personnes âgées trans ont documenté quelques cas anecdotiques dans lesquels des personnes trans vivant avec une démence ont oublié leur transition et se sont réidentifiées avec leur sexe assigné à la naissance (" détransition »). Les communautés trans et leurs alliés encouragent ainsi les personnes trans à s'engager dans la planification de leur fin de vie, notamment à travers la préparation de documents juridiques qui énoncent leurs souhaits relativement à leur identité et à leur expression de genre en cas « d'incapacité » causée par la démence. Bien que de tels documents s'avèrent utiles, nous soutenons que la

* The authors would like to thank the guest editors of this special issue, as well as the editors of the Canadian Journal of Law \& Society, for their invaluable support during the publication process. This research is funded by a Social Sciences and Humanities Research Council of Canada (SSHRC) Insight grant, and we thank them for their financial support.

Canadian Journal of Law and Society / Revue Canadienne Droit et Société, 2020,

Volume 35, no. 2, pp. 367-390. doi:10.1017/cls.2020.13 
planification de la fin de vie est souvent implicitement basée sur des hypothèses cisnormatives et cognonormatives (système normatif basé sur les capacités cognitives). Une telle planification repose sur une conception de l'identité de genre comme étant stable tout au long de la vie ("post-transition ") et suppose que le soi " pré-démence » est mieux équipé pour prendre des décisions que le soi « dément ». Nous concluons en encourageant, sur la base d'une approche intersectionnelle, trans-affirmative, crip-positive et âge-positive, le respect de l'agentivité des personnes trans vivant avec une démence.

Mots clés: Personnes trans et non binaires, démence, planification de fin de vie, cisgenrisme/transphobie, capacitisme/cogniticisme, âgisme, injustices épistémiques.

\section{Dementia and Advance Care Directives: Preparing to Forget Everything... Including Your Gender Identity}

Service providers in a residential aged care facility shared in an interview the story of Edna [...]. Edna had transitioned to female 40 years earlier. Prior to her admission, Edna was given an ultimatum by her son to present as male or never see her grandchildren again. [...] Edna complied and it was not until staff assisted her to shower that they became aware that she was a transgender woman. Edna was reliant on service providers to advocate on her behalf, and they $[\ldots]$ were unsure how to challenge Edna's family and were concerned that doing so would jeopardise her access to her grandchildren. As a consequence of her dementia, Edna lost the capacity to educate staff about her needs, and was more vulnerable to the transphobic demands of her family. She was dependent on others who did not sufficiently understand her transgender needs and she was incapable of self-advocacy. [...] Edna's presentation as a male could be misread as an indication that her trans status was lost because she had dementia. But this was not the case. Rather, dementia provided an opportunity for family members to reassert their own transphobic beliefs, with devastating consequences. (Barrett et al., 2016, 103-104)

The end of life, a period typically comprised of the few months before dying, but that we define more broadly as a potentially extended period in which a person is situated at the end of their life trajectory as opposed to its beginning, is experienced differently among diverse social groups, including trans older adults. ${ }^{1}$ The story of Edna, as described by healthcare professionals to a research team led by Barrett et al. working on trans aging (2016), captures the difficult realities facing trans older adults living with dementia. ${ }^{2}$ It also underscores some of the most contentious current debates in trans communities, such as the question of "detransition," that is the action of not pursuing a sex/gender transition previously instigated or reverting to one's sex/gender assigned at birth (Baril and Silverman, 2019). While most of the

The term trans includes different gender identities, for example transsexual, transgender, nonbinary, gender fluid, and two-spirit people (Baril, 2009).

2 The term dementia includes a number of conditions that can lead to memory, communication and other cognitive changes, such as Alzheimer's disease or vascular dementia. 
literature on "detransition" has focused on trans youth, reflecting a more general ageist bias in trans studies (McGovern, 2014; Siverskog, 2015; Toze, 2018), a surprising number of works in the limited yet growing literature on trans older adults discuss cases of "detransition" in relation to dementia (e.g. Withall, 2014; Latham and Barrett, 2015a; Marshall, Cooper, and Rudnick, 2015; Knauer, 2016; Witten, 2016). Both of these groups-minors and older adults with cognitive disabilities - are groups for which legal capacity ${ }^{3}$ is either absent or questioned (de Boer et al., 2010; Flynn, 2018). While some authors, such as Barrett et al. (2016) cited above, seem skeptical about gender identity "confusion" or the desire to "detransition" and believe these phenomena are explainable through external pressures, others, based on a few anecdotal cases in the literature, believe that dementia, with its related changes, could impact gender identity and expression. Regardless of whether or not they believe in potential gender-identity "confusion," these authors suggest diverse strategies of intervention with trans people living with dementia (TPLWD) (e.g. Marshall, Cooper, and Rudnick, 2015; Peel and McDaid, 2015; Hunter, Bishop, and Westwood, 2016; Westwood, 2016; McFadden, Frankowski, and Witten, 2017; Baril and Silverman, 2019).

The debates concerning "detransition" have elicited responses in both grey and scientific literature regarding how trans people's rights at the end of their lives should be protected, particularly the rights of those facing illnesses and disabilities, including dementia. For example, Louis Bailey (2012), after surveying trans adults' fears and preoccupations regarding aging, concludes by suggesting five bestpractice principles, including the importance of planning ahead in the event of legal "incapacity":

\begin{abstract}
Forward planning: Trans people should be encouraged to make a living will and to write down clear instructions for family and care staff, should they become incapable of caring for themselves. Trans people should also be advised to nominate someone who is sensitive to their needs and best able to advocate on their behalf, should they develop dementia or a similar disorder[; ] this role can be formalised through the use of an Enduring Power of Attorney. (Bailey, 2012, 36)
\end{abstract}

As we demonstrate in this article, institutions and community organizations are also encouraging trans people to engage in end-of-life (legal) planning, ${ }^{4}$ including the preparation of end-of-life documents, for example wills, the naming of a power of attorney, and advance-care directives to guide the substitute decision-maker

3 The Canadian Association for Community Living (2019) defines legal capacity as follows: “The term recognizes two things: the capacity to have rights and the capacity to act upon those rights. In practice, legal capacity ensures that a person is recognized before the law and can make decisions about his or her own life, exercise rights, access the civil and court systems, enter contracts, and speak on his or her own behalf." In Canada, legal capacity is presumed for all individuals, with the exception of minors. The presumption is rebuttable, and thus people living with dementia may be found to lack capacity for making healthcare decisions.

4 We are using the expressions end-of-life (legal) documents and end-of-life (legal) planning in parentheses to highlight the fact that some documents and planning contain components that are legally binding and other components are not. Through the usage of the parenthetical terms, we seek to make clear that we refer to both the legally binding and non-legally binding components of end-of-life planning and documents. 
(SDM) in making decisions in the event of legal "incapacity." This focus on end-oflife preparation is emerging at a time of sweeping trans legal change in Canada, where, after historic neglect, there have been numerous changes, such as explicit protections under human rights law, the addition of an $\mathrm{X}$ sex designation on government documents, the removal of the requirement to have surgery in order to officially change one's sex designation, and greater supports for legally changing one's sex designation and name (Singer, 2019; 2020). Yet, such legal reforms have not eliminated the fact that trans people still face legal problems in many spheres of daily life. The report TRANSforming JUSTICE: Trans Legal Needs Assessment Ontario found that "trans survey respondents reported notably higher rates of justiciable legal problems in comparison to the adult Canadian population" (James et al., 2018, 2).

Indeed, while we acknowledge that a legal approach to the challenges faced by TPLWD has merit, we contend that asking trans people to engage in "forward planning" via end-of-life (legal) documents often rests upon two unproblematized assumptions. First, gender identity and expression seem to be understood as something static, or as what Baril and Silverman (2019) have named a "transaffirmative stable approach," in which "gender identity is seen as a stable component of identity that is undone by dementia, particularly in a cisgenderist environment that doesn't support chosen identity" (Baril and Silverman, 2019, 6). ${ }^{5}$ Following their critique of a "trans-affirmative stable approach," we argue that the attempt to secure trans people's rights through end-of-life (legal) documents leaves insufficient room for gender fluidity, reconfiguration, and evolution. Second, the call for trans people to secure their rights through end-of-life (legal) documents is based on an implicit ableist/sanist/cogniticist ${ }^{6}$ assumption that the self predementia is better suited to making decisions than the self experiencing dementia.

Our objective in this article, as social-science scholars working from an interdisciplinary perspective, is to provide food for thought for legal scholars, based on our expertise in trans studies, social gerontology, and critical dementia studies. By problematizing the two assumptions mentioned above, we demonstrate that the solution proposed by some scholars, activists, and healthcare professionals to deal with the challenges of dementia in the lives of trans older adults, namely the careful preparation of (legal) documents detailing one's wishes, is founded on a non-

The prefix cis is the opposite of trans; a cisgender/cissexual person is therefore a non transgender/ transsexual person (Serano, 2007). Cisgenderism could be considered a synonym to transphobia, but offers the advantage of avoiding the individual pathologization attached to the notion of "phobia." Instead, cisgenderism highlights the structural forms of violence experienced by trans communities (Ansara, 2015; Baril, 2019).

$6 \quad$ Inspired by critical disability studies (Clare, 2009), crip studies (McRuer, 2006; Kafer, 2013) and mad studies (LeFrançois, Menzies, and Reaume, 2013; Gorman and LeFrançois, 2017), which problematize the systems of oppression against disabled people (ableism) and mad and insane people (two terms reclaimed and resignified by activists), the term cogniticism is "understood as an oppressive system that discriminates against people with cognitive/mental disabilities ... at multiple levels, including political, social, medical, legal, economic, and normative levels" (Baril and Silverman, 2019, 12). We use here three terms-ableism/sanism/cogniticism - to highlight the fact that cogniticism, though an excellent term to discuss the oppression experienced by people living with cognitive impairments, can be considered a synonym to sanism and represents a specific form of ableism. 
intersectional $^{7}$ analysis in which biographical continuity (Bury, 1982; Sabat and Harré, 1992; Sandberg, 2018) is privileged both in terms of gender identity/ expression and cognitive ability. In such (legal) documents, potential gender identity fluidity is negated, as one's gender identity/expression is fixed. This occurs regardless of whether one's stated gender identity/expression is masculine, feminine, both, neither, or even fluid, since even a genderfluid person would have to, paradoxically, fix their nonbinaryness. In terms of cognitive ability, biographical continuity manifests in the idea that the decisions made by someone considered cognitively "able" are better than those made by someone living with dementia. In sum, from an intersectional perspective, we critique the cisnormative ${ }^{8}$ and cognonormative ${ }^{9}$ aspects of end-of- life (legal) documents that privilege consistency and biographical continuity.

In order to demonstrate the above-mentioned thesis, we mobilize an array of fields of studies and their theoretical frameworks, ranging from gender and trans studies to disability, crip, ${ }^{10}$ mad, and dementia studies. Our theoretical framework is comprised of philosophical concepts, such as epistemic injustice (including testimonial and hermeneutical injustices, as coined by Fricker, 2007), epistemic violence, epistemic death, and also epistemic resistance (Medina, 2012, 2017). While the difficult realities facing TPLWD addressed in this article seem to concern only a small number of people, Witten (2016) estimates that, globally, there are between approximately 4 and 12.3 million trans individuals over the age of 65 who might develop dementia. Additionally, it is our hope that the reflections offered here will open fruitful conversations between scholars and practitioners in a wide variety of fields of study and practice, and could benefit all people planning their end of life-disabled or not, cis or trans, young or old.

In the following section, we review the literature on trans aging, as well as the literature on trans aging and dementia, and demonstrate how trans people are already disadvantaged when it comes to accessing the legal rights from which they are supposed to benefit. We then present a hypothetical case study of a TPLWD to highlight the complex realities and various forms of oppression, such as cisgenderism and cogniticism, that impact this population. We mobilize the notion of epistemic injustice to analyze the case study as well as the experiences of TPLWD

7 We refer to the definition of intersectionality provided by Crenshaw (1991), in the tradition of black feminist scholars such as the Combahee River Collective (1997) and Patricia Hill Collins (2000), who consider that aspects of identity such as sex, race, class, age, dis/ability, as well as their related systems of oppression, are interlocked.

8 The neologism "cisnormativity," inspired by expressions like heteronormativity and having roots in terms like cisgenderism and cissexism (Serano, 2007), emerged simultaneously in French and English in the work of Baril (2009) and Bauer et al. (2009). Following Baril (2019), who refined the concept in subsequent work, we understand cisnormativity to be the normative component of the cisgenderist system.

9 King $(2016,59)$ coined the terms "cognonormative/cognonormativity" to problematize the norms regarding cognitive abilities in societies that marginalize people with cognitive disabilities, including people living with dementia.

10 We offer the definition of crip theory provided by Baril and Silverman $(2019,12)$ : "Crip theory, coined by Robert McRuer (2006), in a similar way queer theory reclaimed the insult queer, resignifies the insult crippled and represents an anti-assimilationist perspective in disability studies. Anti-ableist and crip perspectives allow us to adopt a critical stance on the biomedical model of dementia that associates it with decline, loss of personhood and lack of agency." 
in general. In the concluding section, we suggest an intersectional approach that critiques the biographical continuity on which end-of-life (legal) planning and documents rely. This intersectional analysis, based on a trans-affirmative, crippositive, and age-positive perspective, aims to offer conceptual and concrete solutions to the dilemmas discussed in the article.

\section{Trans Older Adults Living with Dementia: A Forgotten Reality?}

As the Canadian population ages rapidly and the incidence of dementia rises, an increasing number of Canadians might be deemed "incompetent," making them more vulnerable to various forms of exclusion, discrimination, silencing, and exploitation. While it is beyond the scope of this article to debate various conceptualizations of "incompetence" and legal capacity, it is noteworthy that, as Bach and Kerzner (2010) explain, the notion of capacity in Canada is often "defined to refer to an ability to understand information relevant to making a decision and an ability to appreciate the reasonably foreseeable consequences of a decision or lack of decision. In this sense, 'capacity' refers to the cognitive requisites considered necessary for exercising one's right to legal capacity ..." (Bach and Kerzner, 2010, 16-17). In other words, capacity is based on a person's ability to cognitively understand information and make decisions, rather than on its broader usage in international human rights law which "describes legal capacity as consisting of two components: 'the capacity to hold a right and the capacity to act and exercise the right ..." (Bach and Kerzner, 2010, 16-17). Bach and Kerzner (2010) aim to challenge, as we wish to do here, the often ableist assumptions behind a more restrictive usage of the notion of legal capacity, which could exclude some people with cognitive disabilities (Flynn, 2018). In the case of TPLWD, this ableism is one component of a larger portrait of discrimination, as trans people face widespread mistreatment and barriers in accessing health and social services (Ansara, 2015; Hughes, 2016; Kattari and Hasche, 2016) and are over-represented in statistics on poverty, mental health issues, and exclusion/isolation (Namaste, 2000; Bauer et al., 2009; Bauer and Scheim, 2015). It is noteworthy that all these forms of discrimination and violence are directly linked to social determinants of health that can lead trans people to be at higher risk for developing dementia (Bailey, 2012; Hulko, 2016; Westwood, 2016; Witten, 2016).

These social determinants of health, along with numerous other issues, are explored in the literature on LGBTQ aging (Ward, Rivers, and Sutherland, 2012; Witten and Eyler, 2012; Kia, 2015; King et al., 2019). Within this growing literature, however, publications addressing dementia are quite rare. This literature, both grey (Peel and McDaid, 2015) and academic (Newman and Price, 2012; McGovern, 2014; Adelman, 2016; Barrett et al., 2016; Hughes, 2016; King, 2016; Knauer, 2016; Newman, 2016; Ward and Price, 2016; Westwood and Price, 2016; Hogan, 2017) looks at the particular realities LGBTQ people living with dementia experience in their daily lives, including in institutional settings. However, despite the integration of the " $T$ " in the acronym LGBTQ, much of the aforementioned literature leaves aside trans-specific realities and focuses on LGBQ communities (Namaste, 2000; Ansara, 2015; Baril, 2019; de Vries et al., 2019). As such, trans realities are better 
addressed in the limited but growing literature on trans aging. This pioneering academic literature addresses primarily the forms of discrimination experienced by trans people in their encounters with healthcare providers and the best practices to serve this population (Cook-Daniels, 2006; Persson, 2009; Bailey, 2012; Finkenauer, et al., 2012; Hébert, Chamberland, and Chacha Enriquez, 2012; Witten, 2014; Fabbre, 2015; Siverskog, 2015; Ansara, 2015; Latham \& Barrett, 2015a, 2015b; Toze, 2018; Pearce, 2019; Pang, Gutman, and de Vries, 2019). While some of this literature is empirically based, other publications remain only theoretical, focused on single case studies or on data collected from trans adults of all ages about their fears of aging, leaving little space for the voices of trans older adults. The same can be said of the scarce texts specific to trans and dementia, in both the grey literature (Alzheimer's Australia, 2014; McFadden, Frankowski, and Witten, 2017) and the academic literature (Marshall, Cooper, and Rudnick, 2015; Hunter, Bishop, and Westwood, 2016; Westwood, 2016; Witten, 2016; Baril and Silverman, 2019). Surprisingly, almost without exception, the literature on LGBTQ and dementia discusses "detransition" and gender "confusion."

With a few exceptions, such as Siverskog (2015), Hulko (2016), Wilson, KortesMiller, and Stinchcombe (2018), and King et al. (2019), who adopt an intersectional lens, the above-mentioned literature does not discuss the specific links between TPLWD's multiple identities and the impacts of interlocking oppressions. This gap is surprising given that, from our perspective, TPLWD's experiences cannot be understood uniquely from a trans-studies perspective, a social gerontology perspective, or a critical dementia perspective. Trans adults of all ages, when interviewed and asked about their visions, fears, and preoccupations regarding their future, were particularly concerned with health issues, specifically cognitive impairments. They feared becoming more vulnerable and unable to protest against misgendering and other microagressions (Stein and Almack, 2012; Alzheimer's Australia, 2014; Witten, 2014, 2017; McFadden, Frankowski, and Witten, 2017; Almack, 2019). Indeed, in the Trans MetLife Survey on Later-Life Preparedness and Perceptions in TransgenderIdentified Individuals (TMLS) conducted with 1,963 trans participants, Witten (2016) reported that the participants specifically feared the aging process, in particular becoming disabled, being dependent on others, and developing dementia.

These preoccupations and fears among trans people, anchored in numerous past experiences of discrimination and violence (Persson, 2009; Siverskog, 2015; Hughes and Cartwright, 2015; Chamberland et al., 2016; Wilson, Kortes-Miller, and Stinchcombe, 2018; de Vries et al., 2019; Pang, Gutman, and de Vries, 2019), as well as a few anecdotal cases of "detransition," are what has led some authors and community organizations to discuss the importance of being well prepared for the eventuality of experiencing cognitive disabilities, including ensuring that appointed caregivers are legally recognized. Such recommendations and initiatives for LGBTQ individuals can be found in a number of practical guides such as those produced by Cartwright (2011), the National End of Life Care Programme (2012), and the National Resource Center on LGBT Aging (2014), as well as in articles and other documents discussing LGBT end-of-life issues such as those of Cook-Daniels (2006), Witten (2014), Hughes and Cartwright (2015), Chamberland et al. (2016), Knauer (2016), Cartwright et al. (2018), and de Vries et al. (2019). 
Before analyzing, in the following section, the cisnormative and cognonormative assumptions underlying end-of-life (legal) planning and documents, we would like to end this section by highlighting that the preparation of end-of-life legal documents remains largely inaccessible for most trans people. Although some legal documents, such as advance healthcare directives, can be prepared without a lawyer, and although the Canadian government is trying to inform people about the fact that they can be prepared without legal assistance (Health Law Institute, 2020), many people will still require legal guidance. Knowing that trans people experience several forms of oppression, as well as economic discrimination such as unemployment and homelessness (Namaste, 2000; Serano, 2007; Bauer and Scheim, 2015, Baril, 2019), they often do not have the financial resources to pay for the preparation of these (legal) documents, nor do they consistently have access to professionals, such as notaries and lawyers, who are knowledgeable on trans issues and respectful with trans people. Having such access would help to make the preparation of such documents a positive and safe experience (James et al., 2018). Furthermore, in a context in which many trans people are simply struggling to survive, planning their end of life becomes less important (de Vries et al., 2019; Pang, Gutman, and de Vries, 2019). Wilson, Kortes-Miller, and Stinchcombe (2018) remind us that legal documentation is also complex to understand and navigate. In sum, despite recommendations and incentives to prepare end-of-life (legal) documents, trans individuals remain largely unprepared, without access to the proper information and the support to accompany them in the planning process.

\section{At the Intersection of Ageism, Cisgenderism, and Cogniticism: A Case Study Analyzed Through Epistemic Injustices}

As previously mentioned, some researchers, institutions and community organizations are encouraging trans people to prepare (legal) documents expressing how they would like to be treated in case of "incapacity." For example, the National Resource Center on LGBT Aging published the document Creating End-of-Life Documents for Trans Individuals: An Advocate's Guide (2014), in which they invite trans people to indicate their preferences in terms of chosen name, pronouns, and physical appearance. These preferences are intended to guide the decisions made on their behalf by their SDM. This organization proposed the following form:

During any period of treatment, I direct my physician and all medical personnel to refer to me by the name of irrespective of whether I have obtained a court-ordered name change, changed my gender marker on any identification document, or undergone any transition-related medical treatment. During any period of treatment, I direct my physician and all medical personnel to use the pronoun in reference to me, my chart, my treatment, etc. .... During any period of treatment, if I am unable to personally maintain my appearance, I direct my physician and all medical personnel to do so to the extent reasonably possible ...." (National Resource Center on LGBT Aging, 2014, 2-3)

It could be argued that legal arrangements and documents are not pertinent to the majority of routine "minor" interactions, since advance healthcare directives 
usually address "major" decisions, such as giving permission for certain health procedures. Simultaneously, while directives might include a list of values and principles to guide the SDM, they do not require care providers to perform certain actions, for example in regard to the provision of specific clothing items or the usage of certain pronouns. One could wonder, then, why legal documents may still be relevant to the kinds of gendered interactions we are discussing in this article. We contend that, for many trans individuals, day-to-day interactions involving pronoun usage, type of clothing, etc., are vital aspects of their lives. As a group, TPLWD are in a particularly vulnerable position in which their daily care could become the site of several forms of discrimination. We recognize that the extent to which legal documents can require caregivers to interact with a TPLWD in a certain way is limited. It is thus important for trans individuals to reflect on their choice of SDM to ensure that this person is trans-affirmative or sensitized to trans issues.

Both trans and cis individuals have also been encouraged by diverse associations to revise end-of-life (legal) documents as needed in order to keep them up to date. For example, the Ontario Medical Association (OMA) states, in a document entitled Advance Care Planning: Backgrounder. OMA's End-of-Life Care Strategy (2014): "The Ontario Medical Association (OMA) believes it is important that people make their end-of-life wishes known whatever they are. The evidence shows that patients' care preferences change over time and in accordance with their changing health status and personal circumstances. This underscores the importance of viewing advance care planning as an ongoing process rather than directed toward a static plan.”

While we cannot agree more with the OMA regarding the fact that advance care planning should be an "ongoing process," in reality, these documents become, to reuse the OMA's words, a "static plan" once someone is deemed legally "incompetent." Legal documents can change, evolve, and be rewritten until a person loses legal capacity, at which point their expressed wishes become unchangeable (Diller, 2016). Although we recognize that legal capacity is theoretically variable depending on circumstances and decisions, ${ }^{11}$ in practice, many healthcare providers and family members will interact with PLWD as though they are incapable of making all decisions once they have been determined to have lost decisional capacity in one context. In other words, there appears to be a discrepancy between the law and the application of the law. As explained by authors in critical dementia studies (Bartlett and O'Connor, 2010; Boyle, 2014; Thomas and Milligan, 2018), negative representations of PLWD tend to further discredit their ability to make decisions. Consequently, their legal capacity is not reassessed regularly, often making it "static" rather than changeable. Establishing legal capacity is deeply connected to philosophical and ethical debates on the self and personhood that we can trace back to the 1980s. While we lack the space in this article to engage in the debates around

11 For example, a person might be deemed legally competent to make a minor decision about their health but be deemed incompetent to make a major decision about their health that would require more complicated reasoning and decision-making capacity. 
personhood and legal competence pre- and post-dementia, ${ }^{12}$ it is important to note that there are significantly different positions in this debate, ranging from viewing the person with dementia as an entirely "new" person with new needs to be respected (e.g. Parfit, 1984; Dresser, 1995; Jaworska, 1999) to the position of preserving the wishes of the "previous" self at all cost (e.g. Dworkin, 1986).

For the purposes of this article, we focus on the fact that the turning-point moment at which someone goes from being encouraged to revise and update their legal documents to being discouraged to change them is founded on cognonormative and cisnormative assumptions that rely on a non-intersectional perspective on the self. Although we recognize that, legally, the turning point is based on a person's ability to make specific decisions, in the case of PLWD, they often don't have their capacity tested regularly due to the biases mentioned above. We are aware that removing some people's decision-making agency serves to protect them when they are in positions of vulnerability, and that therefore in some instances, this removal may be justifiable and even beneficial. However, our goal is to question the pervasive delegitimization and invalidation of PLWD's decision-making abilities once they have been deemed legally incompetent. ${ }^{13}$ We recognize that denouncing cisnormative and cognonormative assumptions that underlie legal understandings of competence, and promoting PLWD's agency and decision-making ability, evokes potentially contentious debates.

To better illustrate the above-mentioned cognonormative and cisnormative assumptions that impact the way laws are experienced by TPLWD, we present here a hypothetical case study involving the two lead authors of this article. While hypothetical because it takes place in the future, this case study is anchored in current facts, such as Alexandre being a trans man and Marjorie being his cis partner. It is also based on the few anecdotal cases of TPLWD expressing gender "confusion" or "detransition" discussed in the literature in section two. Imagine that Alexandre is now eighty and has been living with dementia for the past five years. While he is still "functional" in many spheres of his life, he has several periods of confusion each day. For the past few months, there have been many days during which he has forgotten that he transitioned in his late twenties. On those days, he refers to himself as a woman, using feminine pronouns, and insists on being given women's clothing and having his makeup done. Before being diagnosed with dementia, Alexandre decided, with the help of lawyers, to complete detailed end-of-life documents. He designated Marjorie as his SDM, both for his administrative/financial decisions and his personal care. Following a model similar to that proposed by the National Resource Center on LGBT Aging (2014), he stated that in all circumstances he wants to be referred to with masculine pronouns, maintain his masculine gender expression, and be buried and remembered as a man. He noted that returning to a woman's name, and to feminine pronouns and appearance, would constitute cisgenderist violence. When Marjorie, on

12 We invite readers interested in these debates to consult the following references: Parfit (1984); Dworkin (1986); Buchanan (1988); Dresser (1995); Verma and Silberfeld (1997); De Grazia (1999); Jaworska (1999); Davis (2002, 2004); Moody (2003); de Boer et al. (2010); Furberg (2012); Boyle (2014); Hall (2015); Cahill (2018); Flynn (2018).

13 While we would like to discuss the important downsides of giving legal capacity and legal decisionmaking ability to people with severe cognitive disabilities who might not fully understand relevant information, we cannot, in the limited scope of this article, address this issue. 
the days that Alexandre seems "confused" about his gender identity, reminds him that he is a trans man, that he transitioned almost fifty years ago, that he always wanted to be treated as a man, Alexandre becomes aggressive, sad, and depressed, and keeps asking for items of women's clothing. Everyone around him is disconcerted, including the staff at the residence and the rest of his support network. They do not know whether they should relate to him as a woman, or whether they should remain consistent with the identity in which he has been living for the past decades, hence enforcing biographical continuity. What should they do about his external appearance, regarding, for example, body care such as shaving, makeup, and clothing? What should they do about pronouns? Should they continue to inject him with his weekly dose of testosterone to maintain his male hormonal balance? Should they assess the situation on a day-by-day basis and go along with the gender identity he claims on that day? Should they endorse the new feminine identity that he is claiming, and, in that case, what should they do on the days he feels like a man and wants to be treated as one? Under what name and identity should they bury him once he dies? On the one hand, accepting to use a woman's name and feminine pronouns on the days that Alexandre is claiming a female identity could be seen as the most respectful solution in regard to his current wishes. On the other hand, it could be seen as a form of violence in terms of the wishes he expressed in his legal documents. Marjorie also feels caught between two possibilities: doing violence to Alexandre and his trans masculine identity by dismissing the wishes expressed in his end-of-life (legal) documents, or, conversely, doing violence to his current changeable needs and wishes by enforcing a biographical continuity articulated by Alexandre in his pre-dementia life.

We contend that the notion of biographical continuity, used in some intervention strategies with people living with dementia (PLWD), whether trans or cis, is founded in cisnormativity and cognonormativity. According to cisnormative presumptions, individuals are assumed to adhere to a stable gender identity throughout their life, from childhood to old age. Disruption to this stability, whether due to a transition or "detransition," goes against the norm of preserving constancy throughout the life course in terms of gender identity and expression. Such cisnormative presumptions can also increase the chances that someone would be categorized as legally "incompetent," since a person who is "unstable" in their gender identity/expression may be perceived, from a cisnormative and cogniticist point of view, as confused. While gender fluidity or instability may not lead directly to a diagnosis of dementia or to an assessment of legal "incompetence," healthcare professionals and relatives often rely on such cues to initiate diagnoses and/or assessments of legal capacity. In other words, the less gender-identity stability one has, the more one may be perceived as "crazy," "mad," or "demented" (Sandberg, 2018). Gender instability, fluidity or nonbinaryness are, from this point of view, additional signs that a person may be "losing their mind." Paradoxically, such assumptions of stability are also found in transnormative discourses ${ }^{14}$ reproduced by some social, political, medical, and legal institutions, as well as by some trans

14 Limited space prevents us from discussing the notion of transnormativity. For more information, see Johnson (2016). 
people themselves, who propose a similar version of the biographical continuity of gender via the "trapped in the wrong body" discourse (Serano, 2007; Bettcher, 2014). In such discourses, trans people are not seen as experiencing gender identity discontinuity, but are rather seen as individuals who were always, on the inside, inhabiting their self-identified gender.

Similar to cisnormative assumptions, cognonormative assumptions also rely on biographical continuity, in this case regarding the idea that a person with normative cognitive abilities is better suited than a person with cognitive disabilities to making decisions about treatments, care, housing, gender, and so forth. The preparation of end-of-life (legal) documents is based on cogniticism, as cognonormative assumptions are internalized by most people, trans or cis. As Reynolds $(2016,61)$ notes, "ablebodied experience does not automatically afford one insight into disabled experience; on the contrary, it is likely to misunderstand, misjudge, and mischaracterize that experience." This inability to imagine that people with cognitive disabilities still have the ability to make choices and to express their wishes contributes to the devaluation of PLWD as un-participative, meaningless contributors and calls into question the biases manifested in advance care planning, especially the prioritization of cognitive faculties over emotional and experiential input (de Boer et al., 2010; Werner and Doron, 2017; Young et al., 2019). In sum, the cognitive differences brought about by dementia often render PLWD underserving of consideration under the law and could lead to the withholding of basic human rights (Bartlett and O'Connor, 2010; Bartlett, 2014; Cahill, 2018; Thomas and Milligan, 2018; Shakespeare, Zeilig, and Mittler, 2019). A powerful illustration of the devaluation of people with dementia as a result of cognonormativity is found in the following example recounted by a social worker interviewed by Werner and Doron $(2017,1209)$ :

... I asked a judge whether he would be willing to invite the person with dementia [to the court room] before deciding to grant guardianship. He responded vehemently: No way! He didn't even understand what I was asking him .... He said: It is a one-way street; once he/she'd been diagnosed with $\mathrm{AD}$ [Alzheimer's disease] there was no way he [sic] could make decisions, so why invite him/her to appear in court? It is crystal clear that there is a need to appoint a guardian.

Cisgenderism and cogniticism are systems of oppression that work on multiple levels, including the social, political, medical, and legal, as well as epistemological, levels. At the epistemological level, oppression and violence against trans people and/or people with cognitive disabilities discriminate against them as subjects of knowledge. Miranda Fricker coined the notion of "epistemic injustice," a concept in which a "wrong [is] done to an individual specifically in their capacity as a knower." Fricker distinguishes two types of epistemic injustice: "testimonial injustice" and "hermeneutical injustice:"

Testimonial injustice occurs when prejudice causes a hearer to give a deflated level of credibility to a speaker's word; hermeneutical injustice occurs at a prior stage, when a gap in collective interpretive resources puts someone at an unfair disadvantage when it comes to making sense of their social experiences. An example of the first might be that the police do not believe you because you are black; an example of the second might be that you suffer sexual harassment in a culture that still lacks that critical concept. (Fricker, 2007, 1) 
In an article published with Katharine Jenkins, Fricker deepens her notion of "hermeneutical marginalization," seen as a prerequisite of hermeneutical injustice (Fricker and Jenkins, 2017, 268). They contend that "[h]ermeneutical injustice is the injustice of being frustrated in an attempt to render a significant social experience intelligible ... where hermeneutical marginalization is a significant causal factor in that failure. Someone counts as hermeneutically marginalized insofar as they belong to a social group that under-contributes to the common pool of concepts and social meanings" (Fricker and Jenkins, 2017, 268).

It would be possible to say, following authors such as Crichton, Carel, and Kidd (2017) and Young et al. (2019), that PLWD experience both forms of epistemic injustice, as well as forms of hermeneutical marginalization. On the one hand, on the basis on their dementia diagnosis, PLWD experience testimonial injustice because they lose their credibility as speakers. On the other hand, PLWD suffer from hermeneutical injustice since they are disadvantaged in terms of the conceptual tools necessary to make their lived experiences understandable to themselves and others. Indeed, the dominant narratives of dementia, which are marked by loss, decline, irrationality, and incapacity (Bartlett and O'Connor, 2010; Bartlett, 2014; Boyle, 2014; Aubrecht and Keefe, 2016; Ward and Price, 2016; Sandberg, 2018), make it difficult for PLWD to look at their condition from other perspectives. For example, it may be difficult for them to realize that they are oppressed by cogniticism. Furthermore, as Fricker and Jenkins (2017) explain, hermeneutical injustice goes hand in hand with hermeneutical marginalization; it is precisely because PLWD are hermeneutically marginalized and are not seen as legitimate speakers that they are unable to put forward their perspectives on dementia, resulting in an experience of hermeneutical injustice. These three forms of epistemic injustice form a vicious circle in which each feeds on the others. Furthermore, the epistemic injustices in those three forms experienced by PLWD simultaneously shape, and are shaped by, cogniticism. Indeed, being delegitimized on an epistemic level is rooted in cogniticism, but the fact that PLWD remain "hermeneutically marginalized" fuels the cogniticist system because the voices of PLWD are rarely listened to and given credibility. As a result, the cogniticist system remains unchallenged. To return to our hypothetical case study, the fact that Alexandre decided, when preparing his end-of-life (legal) documents, to favour gender identity stability through the continued use of a masculine name, pronouns and appearance, regardless of what his future self might want, gives authority to his cognitively "healthy" mind over his "demented mind," and is based on various forms of epistemic injustice that both derive from, and simultaneously feed, cisnormativity and cognonormativity.

In the spirit of our intersectional approach, we conclude this section by borrowing from the field of critical race studies (Crenshaw, 1991; Hill Collins, 2000; Medina, 2012, 2017), in particular the notion of "epistemologies of ignorance" that is pertinent to the realities of PLWD. Medina $(2012,2017)$ articulates how forms of epistemic injustice can lead to "epistemic death," which occurs when “a subject's epistemic capacities are not recognized" (Medina, 2017, 254). This stems in part from "epistemologies of ignorance," which are active processes that allow dominant groups, white people in the case of Medina and, in the case of this 
article, cognitively abled people, to ignore "social facts, experiences, and meanings that, as a result of racial oppression [and we can add cogniticist oppression], become invisible, inaudible, or simply unintelligible in certain social locations and for certain perspectives that protect themselves from facing their involvement in racial [and cogniticist] oppression with a shield of active ignorance" (Medina, 2017, 247). As illustrated in the above examples, this is precisely what happens in the case of PLWD. Their voices, concerns, perspectives, and realities, are actively forgotten by those around them, and this epistemic injustice is exercised and reproduced through cogniticist notions of "incapacity." In the final section, we reflect on how we can help PLWD exercise their agency.

\section{Trans People Living with Dementia Speak; Can we Listen ${ }^{15}$}

Having explored the cisnormative and cognonormative assumptions underlying end-of-life (legal) planning and documents for TPLWD, how do we combat the epistemic injustices that are the result of such assumptions in order to allow TPLWD to speak not only before they have dementia but also while they have dementia? And how do we ensure that when they do speak, they are heard? Inspired by Medina's (2017) concept of epistemic resistance, and Baril and Silverman's (2019) notion of a "trans-affirmative fluid approach" to TPLWD, we propose foundational reflections to nourish a reconceptualization of capacity and consent for TPLWD during their end of life. As previously stated, this article is not intended to provide definitive answers regarding potential changes to capacity laws and endof-life (legal) documents, but rather to initiate a conversation about how we can best support TPLWD and give voice to their wishes.

We turn for inspiration to Medina's (2017) concept of an epistemology of resistance that gives voice and recognition to those who are systematically silenced through oppression and marginalization. Medina explains that "resisting epistemic oppression requires exerting epistemic friction on the ground, that is, through practices that exert pressure and create trouble so as to halt or disrupt oppressive dynamics" (254). Such resistance, in the form of "epistemic insurrectionary acts" (256) can be carried out at both individual and structural levels as a response to the violence experienced by marginalized groups in their daily lives. Such actions do not have to constitute large gestures; in fact, Medina articulates that "micropractices of resistance are worth pursuing in a sustained and concerted way because, just as any single act of micro-aggression may not do a lot of harm but collectively micro-aggressions help to maintain a culture of intimidation and epistemic violence, micro-activities of resistance ... can help to undermine, weaken, and ultimately destroy such culture" (2017, 258). A similar notion of resistance can be found in Kim Hall's explanation of the concept of "cripistemology," which "considers how cognitive differences can be epistemic resources for developing resistant, transformative knowledge" (2017, 165). Like

As Medina (2017, 256) reminds us, the notion of "epistemic violence" was first coined by Chakravorty Spivak (1988) in her essay "Can the Subaltern Speak?" Our subtitle mobilizes the formula of her title. Indeed, TPLWD and PLWD speak, but too often, based on forms of epistemic violence, are not heard. 
Medina, Hall calls for practices of resistance that we can interpret to mean, in the case of PLWD, the recognition of non-cognonormative forms of knowledge, such as wishes expressed through gestures or nonverbal actions or emotions.

Before conceptualizing what such micro-practices of resistance might look like in the case of TPLWD, it is important to name some of the foundational elements that should underlie such practices or actions. Any approach aiming to combat epistemic injustice and give voice to TPLWD, whether through large actions, such as redefining legal capacity, or micro-actions, such as responding to a look of contempt, must be intersectional. An intersectional approach to the unique challenges facing TPLWD acknowledges how different aspects of identity-including age, cognitive disability, and transness (and possibly other facets of identity, such as race, depending on the individual) — and their associated systems of oppression, for example ageism, cogniticism, and cisgenderism, interact to lead to interlocking forms of violence. For example, people with disabilities of all ages have a history of being pathologized and denied voice and choice when it comes to decisions regarding health, housing, sexuality, and so forth (Clare, 2009). For older adults with disabilities, this ableist violence intersects with ageism, rendering them even more invisible and marginalized, as older adults are often denied rights and treated as incompetent and unproductive subjects (Bartlett, 2014; Boyle, 2014; Thomas and Milligan, 2018; Shakespeare, Zeilig, and Mittler, 2019). When transness is added to this portrait, it can lead, as mentioned earlier, to a reinforcement of the idea that trans older adults with cognitive disabilities are "crazy" due to potential gender non-conformity; in this case, gender identity transformation or disruption adds further "proof" that agency should be removed.

In addition to offering a critique of interlocking forms of oppression, an intersectional approach can also lead to finding interlocking solutions. Baril and Silverman (2019), in their typology of responses to the potential "detransition" of TPLWD, articulate an approach, named a "trans-affirmative fluid approach," that is intersectional, as it brings into dialogue age, disability, and transness. Building on this approach, we posit that any reconceptualization of legal competence and/or end-of-life (legal) planning and documents for TPLWD, or any actions that aim to combat epistemic injustice and improve their lives, should be trans-affirmative, crip-positive, and age-positive. This means that TPLWD should be given the agency to express their current gender, regardless of whether it represents biographical continuity-and be heard. Allowing TPLWD the agency to decide their gender follows a crip-positive perception of dementia, in which cognitive disability is not seen as leading to a decline of personhood or agency. A crip-positive approach values different articulations of wishes that are not necessarily based in cognonormative notions of "rationality." In this sense, a TPLWD should be able to express their desired gender in embodied ways, for example through gestures, body language, clothing, or make-up. The agency to express one's gender in noncognonormative ways should also not be denied due to older age. An age-positive approach encourages self-determination for people of all ages and tries to combat the invisibility and infantilization often imposed upon older adults and that can result, for trans older adults, in the gatekeeping of their gender identity and expression. 
How do we put these principles into action? How do we engage in practices of resistance that support the agency of TPLWD? Following the lead of legal scholars such as Joffe and Montigny (2014) and Diller (2016), who have called for a re-examination of capacity and decision-making for older and disabled Canadians, and Bach and Kerzner, who argue for a new approach "to defining decision-making capability [that] moves beyond the ableist assumptions of capacity law as it now stands in Canada" $(2010,23)$, we too want to see a broader conceptualization of capacity, which takes into consideration the multiplicity of ways that people with cognitive disabilities might express their wishes. Bach and Kerzner explain that people with disabilities can be supported in making decisions, and these supports could "lead to the capacity to express one's intention or will in ways that at least one other person can reasonably describe as meaningful” (2010, 22). Such supports might include having someone help them interpret and represent their communications, explaining options to them in plain language, allowing them ample time over several meetings, and repeating information if necessary (Bach and Kerzner, 2010; Diller, 2016). The idea of offering PLWD supports so they are able to sustain their agency is actively crip-positive and age-positive and aligned with a long history of feminist and disability/crip scholarship that addresses the concept of autonomy through an anti-oppressive lens, theorizing its relational aspects and the importance of interdependence and accessibility (Kafer, 2013; Hall, 2017).

Based on the idea that TPLWD should be better supported in expressing their wishes while they have dementia and not only before, we propose that end-of-life (legal) planning, with its associated documents, be, in the lived experience of TPLWD, an ongoing, fluid, dynamic process. While there are calls for more focus on the process of end-of-life planning rather than its outcome (de Vries et al., 2019), often the process is still conceptualized as occurring before someone has a cognitive disability. We believe the process should be encouraged to continue after the person develops a cognitive disability, right up until their death, a period of time that can range from months to years and during which the person's cognitive abilities will likely fluctuate. While we acknowledge that there are potential downfalls to this approach and that it would present challenges to the legal and healthcare systems and to families, we believe soliciting and supporting TPLWD's wishes in an ongoing manner would generate improvements. This process of actively soliciting and supporting TPLWD's agency can take the form of regular opportunities during which the person is encouraged to express their wishes on a range of topics (not only gender) and during which there is support for nonverbal forms of expression, such as paper and markers if the person wants to draw, or picture cards if they want to select images. Safe environments could be created in which all forms of gender expression are valued, whether that takes the form of badges for different pronouns or diverse items of clothing, make-up, and accessories that could support multiple gender expressions (Baril and Silverman, 2019). Such safe environments cannot be created without accompanying structural changes, for example gender-inclusive bathrooms in care homes, training and sensitization of workers and supportnetwork members, and public sensitization regarding dementia and transness in order to reduce stigma. Finally, TPLWD who have prepared end-of-life (legal) documents in the past should be given the opportunity to review them regularly, 
using supportive measures if necessary, in order to provide ongoing consent or assent. Thus, we are not encouraging trans individuals to forgo the preparation of end-of-life (legal) planning and documents. Rather, we are encouraging TPLWD, and a wide range of actors involved in their lives, to reflect critically on some of the implicit principles, values, and assumptions that influence end-of-life (legal) planning, documents, and laws.

The goal of the supportive measures mentioned above is to obtain ongoing consent or assent, and to ensure that the process of end-of-life (legal) planning is a truly fluid one that resists cisgenderism, cogniticism, and ageism. This necessitates rethinking not only the concept of capacity through a non-cogniticist and noncisnormative lens, but also the concept of consent-away from one that is static, and towards one that is fluid. If legal documents are to be rethought, reaffirmed, and restated on a regular basis by PLWD, these documents should not be seen as a "final" outcome or as one's "final" word. In the same way that sexual consent was rethought by feminists so that it now involves ongoing and affirmative consent, we believe that end-of-life (legal) planning should be implemented with PLWD—as with the rest of the population-as something to be constantly renewed and affirmed.

Although this article has focused on TPLWD, we hope that the reflections put forward will serve as a basis for a broader examination regarding the agency of all people with cognitive disabilities or those who are deemed legally "incompetent" (Bach and Kerzner, 2010; Reynolds, 2016; Crichton, Carel, and Kidd, 2017). We hope that legal scholars and other key actors will take up the challenge of questioning the cogniticist, cisgenderist and ageist presumptions at the heart of notions of capacity and end-of-life (legal) planning and documents for trans communities. New legal narratives are starting to emerge that promote a switch from "substitute decision-making regimes ... [to] supported decision-making which respects the person's autonomy, will and preferences" (Cahill, 2018, 160). Furthermore, some legal scholars have begun to discuss the necessity of intersectional approaches in law in order to better understand the lived experiences of people belonging to multiple marginalized groups so that the law can adequately protect them from oppression, rather than perpetuate harm (Bilge and Roy, 2010; Spade, 2013; Clutterbuck, 2015; Singer, 2020). We strongly encourage this forward movement, in the same way that we encourage the growing activism by people with dementia (Bartlett, 2014) and their inclusion in conversations about collaborative and intersectional law reforms regarding trans and disabled communities. It is time to let (trans) people with dementia speak. It is time to listen.

\section{References}

Adelman, Marcy. 2016. Overcoming barriers to care for LGBT elders with Alzheimer's. Generations - Journal of the American Society on Aging 40 (2): 38-40.

Almack, Kathryn. 2019. "I didn't come out to go back in the closet": Ageing and end-of-life care for older LGBT people. In Older lesbian, gay, bisexual and trans people. Minding the knowledge gaps, ed. Andrew King, Kathryn Almack, Yiu-Tung Suen, and Sue Westwood, 158-171. Oxon: Routledge.

Alzheimer's Australia. 2014. Dementia, transgender and intersex people: Do service providers really know what their needs are? Melbourne: Alzheimer Society. 
Ansara, Y. Gavriel. 2015. Challenging cisgenderism in the ageing and aged care sector: Meeting the needs of older people of trans and/or non-binary experience. Australasian Journal on Ageing 34:14-18.

Aubrecht, Katie, and Janice Keefe. 2016. The becoming subject of dementia. Review of Disability Studies: An International Journal 12 (2 \& 3): 1-19.

Bach, Michael, and Lana Kerzner. 2010. A new paradigm for protecting autonomy and the right to legal capacity. advancing substantive equality for persons with disabilities through law, policy and practice. Ontario: The Law Commission of Ontario.

Bailey, Louis. 2012. Trans ageing. Thoughts on a life course approach in order to better understand trans lives. In Lesbian, gay, bisexual and transgender ageing. Biographical approaches for inclusive care and support, ed. Richard Ward, Ian Rivers, and Mike Sutherland, 51-66. London: Jessica Kingsley Publishers.

Baril, Alexandre. 2009. Transsexualité et privilèges masculins. Fiction ou réalité? In Diversité sexuelle et constructions de genre, ed. Line Chamberland, Blye W. Frank, and Janice Ristock, 263-295. Québec: Presses de l'Université du Québec.

Baril, Alexandre. 2019. An analysis of the underrepresentation of trans professors in Canadian universities. Chiasma: A Site for Thought 5:90-128.

Baril, Alexandre, and Marjorie Silverman. 2019. Forgotten lives: Trans older adults living with dementia at the intersection of cisgenderism, ableism/cogniticism and ageism. Sexualities. https://doi.org/10.1177/1363460719876835.

Barrett, Catherine, Pauline Crameri, J. R. Latham, Carolyn Whyte, and Sally Lambourne. 2016. Person-centered care and cultural safety. The perspective of lesbian, gay, and trans (LGT) people and their partners on living with dementia. In Lesbian, gay, bisexual, and trans individuals living with dementia. Concepts, practice and rights, ed. Sue Westwood and Elizabeth Price, 97-109. Abingdon: Routledge.

Bartlett, Ruth. 2014. Citizenship in action: The lived experiences of citizens with dementia who campaign for social change. Disability \& Society 29 (8): 1291-1304.

Bartlett, Ruth, and Deborah O'Connor. 2010. Broadening the dementia debate. Bristol: The Policy Press.

Bauer, Greta R., and Ayden I. Scheim. 2015. Transgender people in Ontario, Canada: Statistics from the Trans PULSE Project to Inform Human Rights Policy. London, Ontario. University of Western Ontario. http://transpulseproject.ca/wp-content/ uploads/2015/06/Trans-PULSE-Statistics-Relevant-for-Human-Rights-Policy-June2015.pdf (accessed June 1, 2015).

Bauer, Greta R., Rebecca Hammond, Robb Travers, Matthias Kaay, Karin M. Hohencadel, and Michelle Boyce. 2009. "I don't think this is theoretical; this is our lives": How erasure impacts health care for transgender people. The Journal of the Association of Nurses in AIDS Care 20 (5): 348-361.

Bettcher, Talia Mae. 2014. Trapped in the wrong theory: Rethinking trans oppression and resistance. Signs 39 (2): 383-406.

Bilge, Silma, and Olivier Roy. 2010. Discrimination intersectionnelle : La naissance et le développement d'un concept et les paradoxes de sa mise en application en droit antidiscriminatoire. Canadian Journal of Law and Society 25(1): 51-74.

Boyle, Geraldine. 2014. Recognising the agency of people with dementia. Sociology 29 (7): 1130-1144.

Buchanan, Allen. 1988. Advance directives and the personal identity problem. Philosophy and Public Affairs 17:277-302.

Bury, Michael. 1982. Chronic illness as biographical disruption. Sociology of Health \& Illness 4(2): 167-182.

Cahill, Suzanne, ed. 2018. Dementia and human rights. Bristol: Policy Press. 
Canadian Association for Community Living. 2019. What is legal capacity? https://cacl.ca/ 2017/11/15/what-is-legal-capacity/.

Cartwright, Colleen. 2011. Respect my decisions: It's my right! A guide to advance end-of-life care planning for gay, lesbian, bisexual, transgender and intersex people. Lismore. ASLaRC Aged Services Unit of Southern Cross University.

Cartwright, Colleen, Ben White, Lindy Willmott, Malcom Parker, and Gail Williams. 2018. Australian doctors' knowledge of and compliance with the law relating to end-of-life decisions: Implications for LGBTI patients. Culture, Health \& Sexuality 20 (8): 845-857.

Chakravorty Spivak, Gayatri. 1988. Can the subaltern speak? In Marxism and the interpretation of culture, ed. Cary Nelson and Lawrence Grossberg, 271-313. Champaign: University of Illinois Press.

Chamberland, Line, Julie Beauchamp, Jean Dumas, and Olivia Kamgain. 2016. Aîné.e.s LGBT : favoriser le dialogue sur la préparation de leur avenir et de leur fin de vie, et la prise en charge communautaire. Montréal: Chaire de recherche sur l'homophobie, UQAM.

Clare, Eli. 2009. Exile \& pride: Disability, queerness and liberation, 2nd ed. New York: South End Press. (Orig. pub. 1999.)

Clutterbuck, Alyssa. 2015. Rethinking Baker: A critical race feminist theory of disability, Appeal: Review of Current Law and Law Reform 20:51-70.

Combahee River Collective. 1997. A black feminist statement [1977]. In The second wave. A reader in feminist theory, ed. Linda Nicholson, 63-70. New York: Routledge.

Cook-Daniels, Loree. 2006. Trans aging. In Lesbian, gay, bisexual and transgender aging: Research and clinical perspectives, ed. Douglas Kimmel, Tara Rose, and Steven David. Milwaukee: Columbia University Press.

Crenshaw, Kimberlé. 1991. Mapping the margins: Intersectionality, identity politics, and violence against women of color. Stanford Law Review 43 (6): 1241-1299.

Crichton, Paul, Havi Carel, and Ian James Kidd. 2017. Epistemic injustice in psychiatry. BJPsych Bulletin 41: 65-70.

Davis, John K. 2002. The concept of precedent autonomy. Bioethics 16:114-133.

Davis, John K. 2004. Precedent autonomy and subsequent consent. Ethical Theory and Moral Practice 7:267-291.

de Boer, Marike E., Cees M. P. M. Hertogh, Rose-Marie Dröes, Cees Jonker, and Jan A. Eefsting. 2010. Advance directives in dementia: Issues of validity and effectiveness. International Psychogeriatrics 22 (2): 201-208.

DeGrazia, David. 1999. Advance directives, dementia and "the someone else problem." Bioethics 13:373-391.

de Vries, Brian, Gloria Gutman, Áine Humble, Jacqueline Gahagan, Line Chamberland, Patrick Aubert, Janet Fast, and Steven Mock. 2019. End-of-life preparations among LGBT older Canadian adults: The missing conversations. The International Journal of Aging and Human Development 88 (4): 358-379.

Diller, Rebekah. 2016. Legal capacity for all: Including older persons in the shift from adult guardianship to supported decision-making. Fordham Urban Law Journal 43 (3): 494-538.

Dresser, Rebecca. 1995. Dworkin on dementia. Hastings Center Report 25:32-8.

Dworkin, Ronald. 1986. Autonomy and the demented self. The Milbank Quarterly, 64 (Suppl. 2):4-16.

Fabbre, Vanessa D. 2015. Gender transitions in later life: A queer perspective on successful aging. The Gerontologist 55 (1): 144-153. 
Finkenauer, Sabine, Jackson Sherratt, Jean Marlow, and Andrea Brodley. 2012. When injustice gets old: A systemic review of trans aging. Journal of Gay \& Lesbian Social Services 24 (4): 311-330.

Flynn, Eilionóir. 2018. Legal capacity for people with dementia: A human rights approach. In Dementia and Human Rights, ed. Suzanne Cahill, 157-174. Bristol: Bristol University Press, Policy Press.

Fricker, Miranda. 2007. Epistemic Injustice: Power and the Ethics of Knowing. New York: Oxford University Press.

Fricker, Miranda, and Katharine Jenkins. 2017. Epistemic injustice, ignorance and trans experiences. In Routledge Companion to Feminist Philosophy, ed. Ann Garry, Serene J. Khader, and Alison Stone, 268-278. New York: Routledge.

Furberg, Elisabeth. 2012. Advance directives and personal identity: What is the problem? Journal of Medicine and Philosophy 37:60-73.

Gorman, Rachel, and Brenda A. LeFrançois. 2017. Mad studies. In Routledge International Handbook of Critical Mental Health, ed. Bruce M. Z. Cohen, 107-114. London: Routledge.

Hall, Kim Q. 2017. Queer epistemology and epistemic injustice. In The Routledge handbook of epistemic injustice, ed. Ian James Kidd, José Medina, and Gaile Pohlhaus Jr., 158-166. New York: Routledge.

Hall, Margaret Isabel. 2015. Dementia, decision-making, and the modern (adult) guardianship paradigm: Bentley v. Maplewood Seniors Care Society. Canadian Journal of Comparative and Contemporary Law 1 (1): 293-316.

Health Law Institute. 2020. Advance directives, end-of-life law \& policy in Canada. Dalhousie University. Eol.law.dal.ca/?page_id=231

Hébert, William, Line Chamberland, and Mickael Chacha Enriquez. 2012. Les aîné-es trans : une population émergente ayant des besoins spécifiques en soins de santé, en services sociaux et en soins liés au vieillissement. Frontières 25 (1): 57-81.

Hill Collins, Patricia. 2000. Black feminist thought: Knowledge, consciousness, and the politics of empowerment, 2nd ed. New York: Routledge. (Orig. pub. 1990.)

Hogan, Sally. 2017. Diversity in sexuality combined with a diagnosis of dementia leads to poor health outcomes for LGBTIQ older persons. Australian Nursing \& Midwifery Journal 25 (5): 24.

Hughes, Mark. 2016. Providing responsive services to LGB individuals with dementia. In lesbian, gay, bisexual, and trans individuals living with dementia. Concepts, practice and rights, ed. Sue Westwood and Elizabeth Price, 83-96. Abingdon: Routledge.

Hughes, Mark, and Colleen Cartwright. 2015. Lesbian, gay, bisexual and transgender people's attitudes to end-of-life decision-making and advance care planning. Australasian Journal on Ageing 34 (2): 39-43.

Hulko, Wendy. 2016. LGBT individuals and dementia. An intersectional approach. In Lesbian, Gay, bisexual, and trans individuals living with dementia. Concepts, practice and rights, ed. Sue Westwood and Elizabeth Price, 35-50. Abingdon: Routledge.

Hunter, Chryssy, Jenny-Anne Bishop, and Sue Westwood. 2016. The complexity of trans/ gender identities. Implications for dementia care. In Lesbian, gay, bisexual, and trans individuals living with dementia. Concepts, practice and rights, ed. Sue Westwood and Elizabeth Price, 124-137. Abingdon: Routledge.

James, J., Greta Bauer, Ryan Peck, David Brennan, and Nicole Nussbaum. 2018. Legal problems facing trans people in Ontario. TRANSforming JUSTICE Summary Report 1(1).

Jaworska, Agnieszka. 1999. Respecting the margins of agency: Alzheimer's patients and the capacity to value. Philosophy and Public Affairs 28:105-138. 
Joffe, Kerri, and Edgar-Andre Montigny. 2014. Decisions, decisions: Promoting and protecting the rights of persons with disabilities who are subject to guardianship. Ontario: The Law Commission of Ontario.

Johnson, Austin H. 2016. Transnormativity: A new concept and its validation through documentary film about transgender men. Sociological Inquiry 20 (10): 1-27.

Kafer, Alison. 2013. Feminist, queer, crip. Bloomington: Indiana University Press.

Kattari, Shanna K., and Leslie Hasche. 2016. Differences across age groups in transgender and gender non-conforming people's experiences of health care discrimination, harassment, and victimization. Journal of Aging and Health 28 (2): 28-306.

Kia, Hannah. 2015. Hypervisibility: Toward a conceptualization of LGBTQ aging. Sexuality Research and Social Policy 13 (1): 46-57.

King, Andrew. 2016. Queer(y)ing dementia - Bringing queer theory and studies of dementia into dialogue. In Lesbian, gay, bisexual, and trans individuals living with dementia. Concepts, practice and rights, ed. Sue Westwood and Elizabeth Price, 51-64. Abingdon: Routledge.

King, Andrew, Kathryn Almack, Yiu-Tung Suen, and Sue Westwood, eds. 2019. Older lesbian, gay, bisexual and trans people. Minding the knowledge gaps. New York: Routledge.

Knauer, Nancy J. 2016. LGBT individuals living with dementia. rights and capacity issues in the United States. In Lesbian, gay, bisexual, and trans individuals living with dementia. Concepts, practice and rights, ed. Sue Westwood and Elizabeth Price, 173-189. Abingdon: Routledge.

Latham, J. R., and Catherine Barrett. 2015a. Trans health and ageing: An evidence-based guide to inclusive services. Melbourne, Australia. Australian Research Centre in Sex, Health and Society, La Trobe University.

Latham, J. R., and Catherine Barrett. 2015b. Gender is just part of who I am: Stories from trans Australians: Exploring the experiences and needs of trans people for health and aged care services. Melbourne, Australia: Australian Research Centre in Sex, Health and Society, La Trobe University.

LeFrançois, Brenda A., Robert Menzies, and Geoffrey Reaume, eds. 2013. Mad matters: A critical reader in Canadian mad studies. Toronto: Canadian Scholars' Press.

Marshall, Jeanine, Michael Cooper, and Abraham Rudnick. 2015. Gender dysphoria and dementia: A case report. Journal of Gay \& Lesbian Mental Health 19:112-117.

McFadden, Susan H., Scott Frankowski, and Tarynn Witten. 2017. Anticipating the possibility of developing dementia: Perspectives of older transgender/intersex persons. http://www.alzheimer-europe.org/content/download/24282/173003/file/P18.5\% 20Mcfadden.pdf.

McGovern, Justine. 2014. The forgotten: Dementia and the aging LGBT community. Journal of Gerontological Social Work 57:845-857.

McRuer, Robert. 2006. Crip theory: Cultural signs of queerness and disability. New York: New York University Press.

Medina, José. 2012. The epistemology of resistance: Gender and racial oppression, epistemic injustice, and resistant imaginations. New York: Oxford University Press.

Medina, José. 2017. Epistemic injustice and epistemologies of ignorance. In Routledge companion to philosophy of race, ed. Paul C. Taylor, Linda Martin Alcoff, and Luvell Anderson, 247-260. New York: Routledge.

Moody, Janis. 2003. Dementia and personhood: Implications for advance directives. Nursing Older People 15 (4): 18-21.

Namaste, Viviane K. 2000. Invisible lives: The erasure of transsexual and transgendered people. Chicago: The University of Chicago Press. 
National End of Life Care Programme. 2012. The route to success in end of life care: Achieving quality for lesbian, gay, bisexual and transgender people. https://www. england.nhs.uk/improvement-hub/wp-content/uploads/sites/44/2017/10/End-ofLife-Care-Route-to-Success-Achieving-Quality.pdf.

National Resource Center on LGBT Aging. 2014. Creating end-of-life documents for trans individuals: An advocate's guide. https://www.whitman-walker.org/Guides\%20PDF/ End\%20of\%20Life\%20Planning.pdf.

Newman, Roger. 2016. The needs and rights of LGBT carers of individuals with dementia: A personal journey. In Lesbian, gay, bisexual, and trans individuals living with dementia. Concepts, practice and rights, ed. Sue Westwood and Elizabeth Price, 190-202. Abingdon: Routledge.

Newman, Roger, and Elizabeth Price. 2012. Meeting the needs of LGBT people affected by dementia. The story of the LGBT dementia support group. In Lesbian, gay, bisexual and transgender ageing: Biographical approaches for inclusive care and support, ed. Richard Ward, Mike Sutherland, and Ian Rivers, 103-109. London: Jessica Kingsley Publishers.

Ontario Medical Association (OMA). 2014. Advance care planning: backgrounder. OMA's end-of-life care strategy. Ontario. OMA. https://content.oma.org//wp-content/ uploads/advancedcareplanning.pdf.

Pang, Celeste, Gloria Gutman, and Brian de Vries. 2019. Later life care planning and concerns of transgender older adults in Canada. International Journal of Aging \& Human Development 89 (1): 39-56.

Parfit, Derek. 1984. Reasons and persons. Oxford: Oxford University Press.

Pearce, Ruth. 2019. Trans temporalities and non-linear ageing. In Older lesbian, gay, bisexual and trans people. Minding the knowledge gaps, ed. Andrew King, Kathryn Almack, YiuTung Suen, and Sue Westwood, 61-74. Oxon: Routledge.

Peel, Elizabeth, and Sam McDaid. 2015. "Over the Rainbow" lesbian, gay, bisexual and trans people and dementia project: Summary report. Worcester: Institute of Health and Society.

Persson, Diane I. 2009. Unique challenges of transgender aging: implications from the literature. Journal of Gerontological Social Work 52:633-646.

Reynolds, Joel Michael. 2016. The ableism of quality of life judgments in disorders of consciousness: Who bears epistemic responsibility? AJOB Neuroscience 7 (1): 59-61.

Sabat, Steven, and Rom Harré. 1992. The Construction and deconstruction of self in Alzheimer's disease. Ageing and Society 12 (4): 443-461.

Sandberg, Linn J. 2018. Dementia and the gender trouble?: Theorising dementia, gendered subjectivity and embodiment. Journal of Aging Studies 45:25-31.

Serano, Julia. 2007. Whipping girl. A transsexual woman on sexism and the scapegoating of femininity. Berkeley: Seal Press.

Shakespeare, Tom, Hannah Zeilig, and Peter Mittler. 2019. Rights in mind: Thinking differently about dementia and disability. Dementia 18 (3): 1075-1088.

Singer, Samuel. 2020 forthcoming. Trans Rights are Not Just Human Rights: Legal Strategies for Trans Justice. Canadian Journal of Law and Society.

Singer, Samuel. 2019. Trans competent lawyering. In LGBTQ2+ law: Practice issues and analysis, ed. Joanna Radbord, 159-186. Toronto: Emond Publishing.

Siverskog, Anna. 2015. Ageing bodies that matter: Age, gender and embodiment in older transgender people's life stories. NORA-Nordic Journal of Feminist and Gender Research 23 (1): 4-19.

Spade, Dean. 2013. Intersectional resistance and law reform. Signs: Journal of Women in Culture and Society 38 (4): 1031-1055. 
Stein, Gary L., and Kathryn Almack. 2012. Care near the end of life. The concerns, needs, and experiences of LGBT elders. In Lesbian, gay, bisexual and transgender ageing. Biographical approaches for inclusive care and support, ed. Richard Ward, Ian Rivers, and Mike Sutherland, 114-131. London: Jessica Kingsley Publishers.

Thomas, Carol, and Christine Milligan. 2018. Dementia, disability rights and disablism: Understanding the social position of people living with dementia. Disability \& Society 33 (1): 115-131.

Toze, Michael. 2018. Developing a critical trans gerontology. British Journal of Sociology: $1-20$.

Verma, Sarita, and Michel Silberfeld. 1997. Approaches to capacity and competency: The Canadian view. International Journal of Law and Psychiatry 20 (1): 35-46.

Ward, Richard, Ian Rivers, and Mike Sutherland, eds. 2012. Lesbian, gay, bisexual and transgender ageing. Biographical approaches for inclusive care and support, London: Jessica Kingsley Publishers.

Ward, Richard, and Elizabeth Price. 2016. Reconceptualising dementia. Toward a politics of senility. In Lesbian, gay, bisexual, and trans individuals living with dementia. Concepts, practice and rights, ed. Sue Westwood and Elizabeth Price, 65-77. Abingdon: Routledge.

Werner, Perla, and Israel(Issi) Doron. 2017. Alzheimer's disease and the law: Positive and negative consequences of structural stigma and labeling in the legal system. Aging and Mental Health 21 (11): 1206-1213.

Westwood, Sue. 2016. Gender, sexuality, gender identity and dementia. (In)equality issues. In Lesbian, gay, bisexual, and trans individuals living with dementia. Concepts, practice and rights, ed. Sue Westwood and Elizabeth Price, 21-34. Abingdon: Routledge.

Westwood, Sue, and Elizabeth Price, eds. 2016. Lesbian, gay, bisexual, and trans individuals living with dementia. Concepts, practice and rights. Abingdon: Routledge.

Wilson, Kimberley, Katherine Kortes-Miller, and Arne Stinchcombe. 2018. Staying out of the closet: LGBT older adults' hopes and fears in considering end-of-life. Canadian Journal on Aging 37 (1): 22-31.

Withall, Liz. 2014. Dementia, transgender and intersex people: Do service providers really know what their needs are? Australia: Alzheimer's Australia.

Witten, Tarynn M. 2014. End of life, chronic illness, and trans-identities. Journal of Social Work in End-of-Life \& Palliative Care 10 (1): 34-58.

Witten, Tarynn M. 2016. Trans people anticipating dementia care. Findings from the Transgender MetLife Survey. In Lesbian, gay, bisexual, and trans ${ }^{*}$ individuals living with dementia. Concepts, practice and rights, ed. Sue Westwood and Elizabeth Price, 111-123. Abingdon: Routledge.

Witten, Tarynn M. 2017. Health and well-being of transgender elders. Annual Review of Gerontology and Geriatrics 37 (1): 27-42.

Witten, Tarynn M., and A. Evan Eyler. 2012. Gay, lesbian, bisexual and transgender aging. Challenges in research, practice and policy. Baltimore: Johns Hopkins University Press.

Young, Jessica A., Christopher Lind, J. B. Orange, and Marie-Y. Savundranayagam. 2019. Expanding Current understandings of epistemic injustice and dementia: Learning from stigma theory. Journal of Aging Studies 48:76-84.

Alexandre Baril Ph.D.

Associate Professor,

School of Social Work,

University of Ottawa

abaril@uOttawa.ca 
Alexandre Baril et al.

Marjorie Silverman Ph.D.

Associate Professor,

School of Social Work,

University of Ottawa

marjorie.silverman@uOttawa.ca

Marie-Claire Gauthier Ph.D. Candidate

School of Social Work,

University of Ottawa

mgaut170@uOttawa.ca

Maude Lévesque Ph.D. Candidate

School of Social Work,

University of Ottawa

mleve031@uOttawa.ca 